\title{
Sphenoid sinusitis: a rare cause of ischaemic stroke
}

\author{
Kenneth Stuart Young, ${ }^{1}$ Jian Shen Kiam, ${ }^{2}$ Kneale Metcalf, ${ }_{1}^{3}$ Ramez Nassif ${ }^{2}$
}

${ }^{1}$ York Hospital, Health Education England Yorkshire and Humber, Leeds, UK

${ }^{2}$ Ear Nose and Throat Department, Norfolk and Norwich University Hospital, Norwich, UK

${ }^{3}$ Neurosciences, Norfolk and Norwich University Hospitals NHS Trust, Norwich, UK

Correspondence to Dr Kenneth Stuart Young; kenneth.young2@nhs.net

Accepted 5 July 2021

Check for updates

(c) BMJ Publishing Group Limited 2021. No commercial re-use. See rights and permissions. Published by BMJ.

To cite: Young KS, Kiam JS, Metcalf K, et al. BMJ Case Rep 2021;14:e242943. doi:10.1136/bcr-2021242943

\section{SUMMARY}

We present the case of a 61-year-old woman who presented to the accident and emergency department with an ischaemic stroke, on a background of receiving intravenous and oral antibiotics to treat chronic left sphenoid sinusitis. Initially presenting with right-sided weakness and aphasia, a diagnosis of acute ischaemic stroke was made. Antibiotics had been commenced 1 month prior to the ischaemic stroke. Imaging at that time showed changes in keeping with chronic sphenoid sinusitis along with a small dehiscence in the lateral wall of the left sphenoid sinus and thrombosis of the left superior ophthalmic vein. During that admission blood cultures grew Streptococcus constellatus, a member of the Streptococcus milleri group. We discuss the unusual aetiology of this stroke, the emerging evidence associating chronic rhinosinusitis with stroke and the complex multidisciplinary approach required for management in this case.

\section{BACKGROUND}

Stroke is a common condition in the UK with a reported incidence of $1.36 / 1000$ per year. ${ }^{1}$ Although stroke deaths in the UK have been falling with improved management of vascular risk factors, ${ }^{2}$ stroke is still a common condition, associated with significant worldwide mortality and longterm disability. ${ }^{3}$

Ischaemic stroke is defined as brain, spinal cord or retinal cell death attributed to ischaemia, with the most common aetiologies for ischaemic stroke being atherosclerosis, cardiogenic emboli and small vessel disease. $^{3}$

Other causes of stroke include prothrombotic states such as protein $\mathrm{C}$ and $\mathrm{S}$ deficiency and vasculitis such as granulomatous angiitis, valvular disease and patent foramen ovale with associated right-toleft shunt. ${ }^{4}$

Sinusitis is defined as 'an inflammatory disorder of the paranasal sinuses'. It can be classified into acute and chronic, with chronic sinusitis characterised by signs and symptoms of sinus inflammation persisting for at least 12 weeks. ${ }^{5}$ Isolated sphenoid sinusitis may present with non-specific clinical features, most commonly patients present with headache. ${ }^{6}$

Chronic sphenoid sinusitis can be broadly classified into bacterial and fungal, with bacterial being the more common aetiology in isolated disease. Management for chronic bacterial sinusitis takes the form of targeted antibiotics, intranasal corticosteroids and topical decongestants. Surgical intervention can be considered if medical management is unsuccessful after a period of 6-8 weeks. ${ }^{6}$

\section{CASE PRESENTATION}

A 61-year-old woman presented with sudden onset right-sided weakness and aphasia. She presented outside of the time window for intravenous thrombolysis and was therefore initially managed with aspirin $300 \mathrm{mg}$ once daily.

Prior to presenting with this ischaemic stroke, the patient had recently been admitted twice to hospital.

Six weeks previously she presented with severe headaches with elevated erythrocyte sedimentation rate (ESR) and C-reactive protein (CRP). At this point, she was commenced on a reducing course of prednisolone with a working diagnosis of giant cell arteritis. A temporal artery biopsy was pending and at the point of admission with ischaemic stroke, the patient was taking $30 \mathrm{mg}$ of prednisolone once daily.

Four weeks prior to the index stroke, the patient presented with ongoing headache and new left eye proptosis, conjunctival injection and restriction of eye movements due to pain. An MRI was performed which showed induration of intraorbital fat with left superior ophthalmic vein thrombosis and associated opacification of both sphenoid sinuses (figures 1-3). Subsequently, a high-resolution CT scan was undertaken to further image the orbits and paranasal sinuses. CT scan showed evidence of chronic sphenoid sinusitis with sinus opacification and reactive bone sclerosis. A breach to the lateral wall of the left sphenoid sinus which communicated with the cavernous sinus was also noted.

During this admission, the patient had raised inflammatory markers with a white cell count of $21.1\left(10^{9} / \mathrm{L}\right)$, neutrophils $20.52\left(10^{9} / \mathrm{L}\right)$, CRP $198 \mathrm{mg} / \mathrm{L}$ and ESR of $71 \mathrm{~mm} /$ hour.

Blood cultures were performed due to fever and these grew Streptococcus constellatus-the source of this bacteraemia was felt to be from the patient's sphenoid sinusitis.

A diagnosis of left superior ophthalmic vein thrombosis due to sphenoid sinusitis was made and the patient was commenced on treatment dose low-molecular-weight heparin. On microbiology advice, the patient was commenced on intravenous ceftriaxone and oral metronidazole with an initial proposed duration of 6 weeks.

Other medical history included migraine, chronic kidney disease, osteoporosis, hypertension, gout and glaucoma.

Medication on admission included prednisolone $30 \mathrm{mg}$ once daily, dalteparin 10000 units once daily, ceftriaxone $2 \mathrm{~g}$ intravenously two times per day and metronidazole $400 \mathrm{mg}$ two times per day.

Concern regarding an alternative aetiology was raised in this case given the recent admissions and treatment for chronic sphenoid sinusitis. 


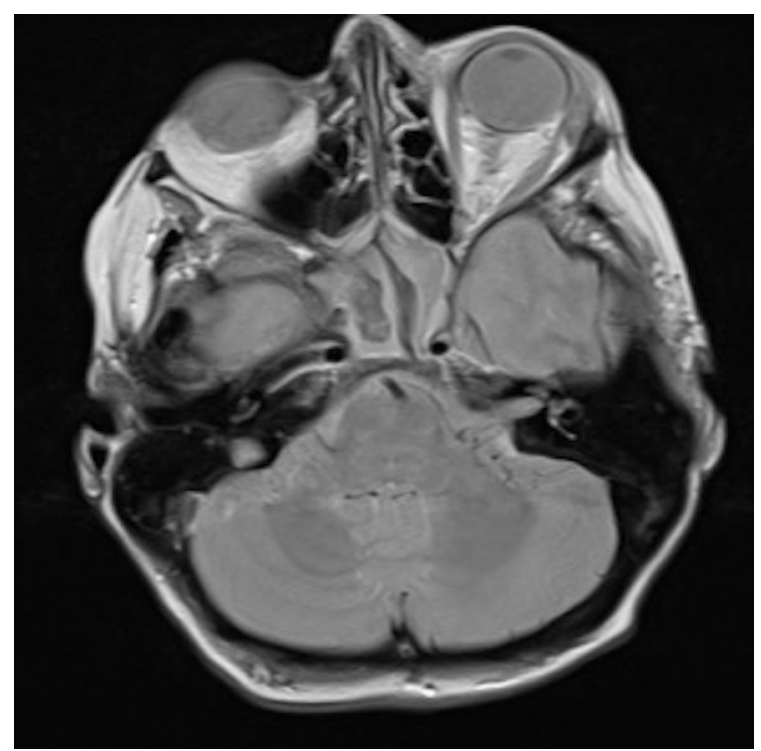

Figure 1 Image taken from MRI scan performed when the patient presented with left eye proptosis with induration of periorbital fat.

Multidisciplinary opinions were sought in order to initiate appropriate management of this ischaemic event.

Further investigation in the form of MRI showed unchanged sphenoid sinusitis extending into the cavernous sinus and surrounding the left middle cerebral artery, evidence of inflammatory tissue encasing the supraclinoid carotid artery and infarction in the anterior midbrain.

\section{Examination at time of presentation}

Right arm and leg weakness 2/5 MRC (medical research council) power grading, moderately severe expressive aphasia and rightsided facial droop were noted.

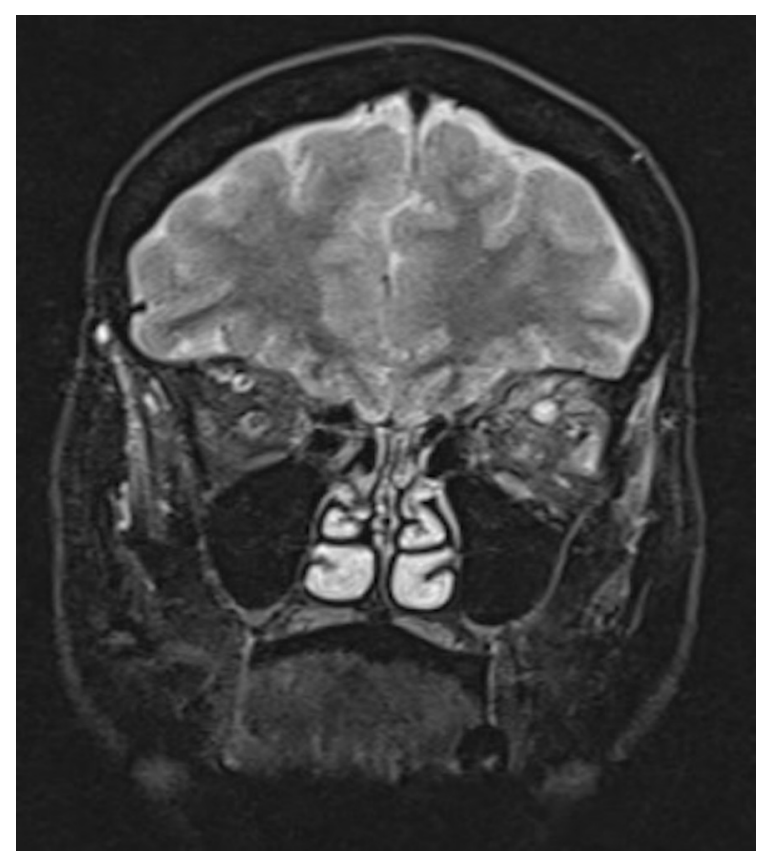

Figure 2 Image taken from MRI scan performed when the patient presented with left eye proptosis. Enlarged thrombosed left superior ophthalmic vein with enlargement and oedema of the intraorbital fat and muscles.

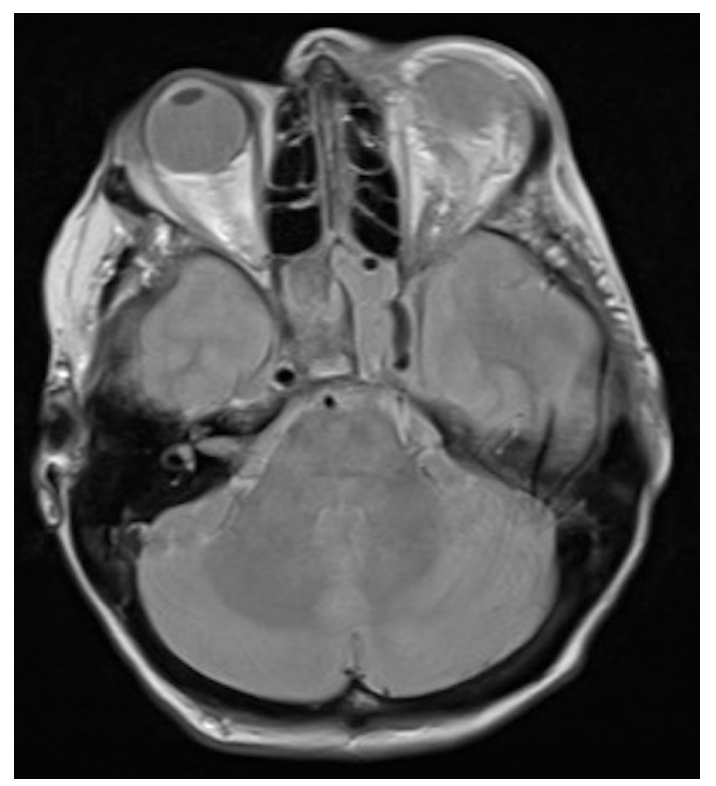

Figure 3 Image taken from MRI scan performed when the patient presented with left eye proptosis. Opacified left sphenoid sinus in keeping with left sphenoid sinusitis causing left superior ophthalmic vein thrombosis and left eye proptosis.

No active nasal symptoms and no pupillary defects were noted.

\section{INVESTIGATIONS}

\section{Relevant investigations}

High-resolution CT scan of the brain on admission with left eye proptosis (prior to index stroke): thrombosis of the left superior ophthalmic vein, no bony destruction or soft tissue infiltration to suggest osteomyelitis or aggressive fungal disease. Opacification of the sphenoid sinuses with reactive sclerosis and mild expansion of the wall of the right sphenoid sinus (in keeping with chronic sinusitis). Breach in the lateral wall of the left sphenoid sinus which communicates with the adjacent cavernous sinus.

CT scan of the brain on admission with ischaemic stroke: no intracranial haemorrhage, small established left frontal and basal ganglia infarcts.

USS carotid Doppler: normal study.

Bloods: HIV, antinuclear antibody screen and antineutrophil cytoplasmic antibodies (ANCA) negative. White cell count 12.1 $\left(10^{9} / \mathrm{L}\right)$, neutrophils $11.64\left(10^{9} / \mathrm{L}\right)$, ESR $35 \mathrm{~mm} /$ hour, creatine $146 \mu \mathrm{mol} / \mathrm{L}$ and estimarted glomerular filtration rate (eGFR) $33 \mathrm{~mL} / \mathrm{min} / 1.73 \mathrm{~m}^{2}$.

\section{MRI imaging}

In figures 1-3, MRI preischaemic infarct reveals enlargement and thrombosis of the left superior ophthalmic vein, sagittal fullness of the left cavernous sinus, moderate opacification of both sphenoid sinuses and intracavernous carotid artery appear normal.

In figures 4 and 5, MRI postischaemic infarct reveals unchanged left sphenoid sinusitis which extends into the left cavernous sinus and around the left middle cerebral artery (MCA), extension of the left acute infarct of the left basal ganglia which involves the anterior midbrain, no evidence of an intracranial abscess or basal meningitis and evidence of inflammatory tissue encasing the supraclinoid internal carotid artery (ICA). 


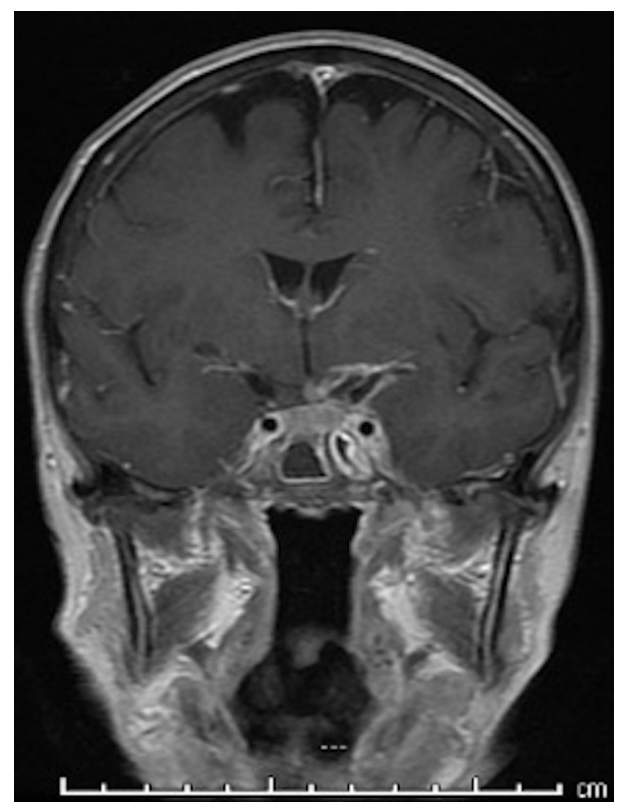

Figure 4 Image taken from MRI scan performed postischaemic infarct. Enlarged left cavernous sinus. Mural and leptomeningeal enhancement of the supra clinoid carotid artery and terminal carotid bifurcation in keeping with inflammation.

\section{DIFFERENTIAL DIAGNOSIS}

Given the complexity of the case a wide differential diagnosis was considered. The main differential was an ischaemic stroke in a patient who was fully anticoagulated with low-molecular-weight heparin. However, given her recent attendances with suspected

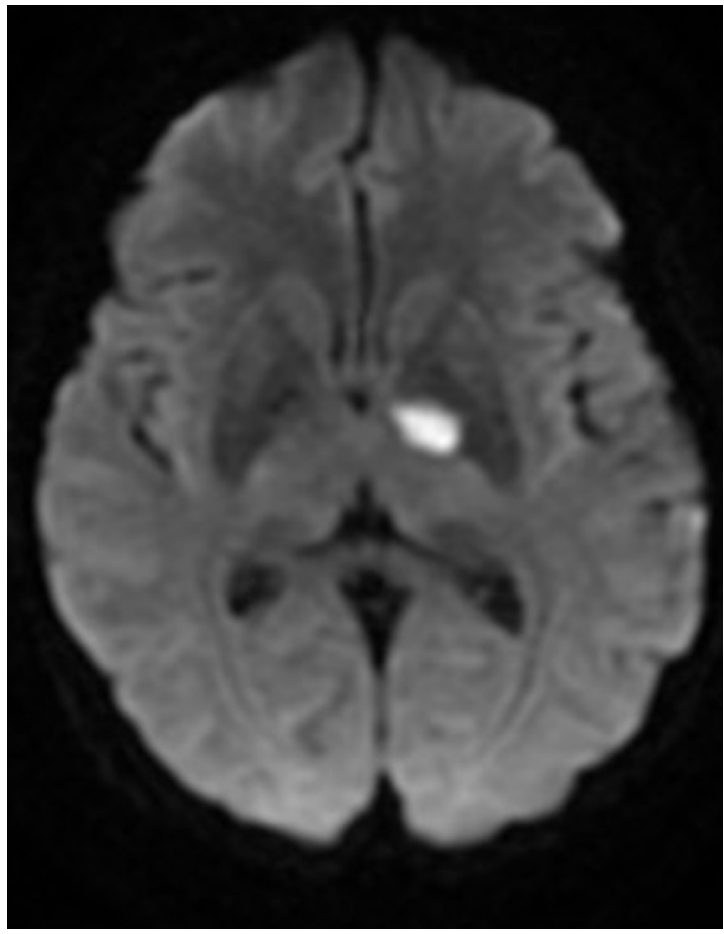

Figure 5 Image taken from MRI scan performed postischaemic infarct. Diffusion weighted imaging showing acute left striatocapsular infarct-in the territory of anterior choroidal (terminal branch of the supraclinoid carotid artery) — felt to be secondary to arteritis caused by left sphenoid sinusitis. giant cell arteritis and sphenoid-sinusitis vasculitis, skull bases osteomyelitis with intracranial extension and cavernous sinus thrombosis were all considered as possible differentials.

\section{TREATMENT}

Initial management took the form of aspirin $300 \mathrm{mg}$ once daily, low-molecular-weight heparin was stopped until imaging was performed.

An Ears Nose and Throat review was requested and it was felt that while there was still evidence of left sphenoid sinus opacification radiologically this was felt to have improved. There was no radiological evidence anterior skull base osteomyelitis or cavernous sinus thrombosis. No acute ENT surgical intervention was required. The patient was recommended to complete a 6-week course of antibiotics and review in outpatient clinic to plan further management.

Due to the patient being admitted on low-molecular-weight heparin, a haematology opinion was sought: given a history of superior ophthalmic vein thrombosis and new ischaemic stroke, it was recommended that the patient should receive treatment with a dose of low-molecular-weight heparin and clopidogrel $75 \mathrm{mg}$ once daily (aspirin stopped). The haematology team noted that there was possible 'thrombin-like activity' of S. constellatus, questioning whether that also contributed to the ischaemic stroke.

The case was discussed with rheumatology and it was felt that now there was a clear aetiology for the patient's symptoms the diagnosis of giant cells arteritis was unlikely and steroids could be weaned.

\section{OUTCOME AND FOLLOW-UP}

The patient was discharged home after a period of inpatient stroke rehabilitation. At recent clinical follow-up, she mobilises independently with a stick; her expressive aphasia has improved and can now hold a fluent conversation (however finds that this requires quite a lot of effort). She does not report any cognitive difficulties and is independent in her activities of daily life.

She has also been followed up in the ENT outpatient clinic where she remains asymptomatic with no nasal or ocular symptoms. Chronic rhinitis was evident on nasal endoscopy but there was no evidence of pus or mucoid discharge. She will have a repeat MRI scan which will be used to plan further intervention

\section{DISCUSSION}

Recent literature has shown that chronic rhinosinusitis statistically significantly increases the risk of both ischaemic and haemorrhagic stroke even when adjusted for age and gender.

Intracranial complication such as empyema, meningitis and cavernous sinus thrombosis are well-recognised complications of paranasal sinusitis. ${ }^{89}$

However, the mechanism by which sphenoid sinusitis causes ischaemic infarction has not yet been fully described. Some authors postulate that the proximity of the internal carotid artery to the lateral wall of an inflamed sphenoid sinus is important. ${ }^{10}$ This may be coupled with exposure of ICA to nasal sinus mucosal and proinflammatory cytokines. The integrity of the sphenoid sinus may be breached contributing to this exposure. ${ }^{10}$ Ongoing inflammation or infection may result in stenotic or thrombotic changes within the cavernous portion of the ICA. ${ }^{8} 10$

The role of immunosuppression has also been postulated by some authors. One report demonstrates cerebral infarctions associated with isolated sphenoid sinusitis in the posttransplant period. This patient had been exposed to high-dose 
corticosteroids (as was the case in our patient due to suspected giant cell arteritis). ${ }^{11}$

S. constellatus is a member of the Streptococcus milleri group, which is made up of three organisms-Streptococcus intermedius, Streptococcus anginosus and S. constellatus. They are microaerophilic bacteria. They often exist as commensal organisms in the mucosa or oral and oropharyngeal tracts. ${ }^{11}$ Organisms from the Streptococcus milleri group also show a propensity to form abscess in the head and neck. ${ }^{12}$ In sinusitis, they have been associated with localised extensions, ${ }^{11}$ intraorbital abscess and cavernous sinus thrombosis. ${ }^{13}$

Previous in vitro studies of the Streptococcus milleri group showed that only S. constellatus had thrombin-like activity. It was postulated pathologically that may lead to increase fibrin production and therefore increased fibrin/platelet clots. ${ }^{14}$ This mechanism may have also contributed to this patient's higher risk of ischaemic stroke.

In summary, we present an interesting case of chronic sphenoid sinusitis felt to be secondary to $S$. constellatus resulting in dehiscence of the lateral wall of the left sphenoid sinus. Subsequent inflammation of the cavernous portion of the ICA led to an ischaemic infarct in a patient who was immunosuppressed due to high-dose corticosteroids.

This case highlights a rare but important intracranial complication of sinusitis as well as the importance that specific microorganisms play. It highlights the importance of a multidisciplinary

\section{Learning points}

- This interesting case highlights a rare but important complication of sphenoid sinusitis as well as emerging evidence that patients with chronic rhinosinusitis are at an increased risk of stroke.

- The importance of consideration of individual causative pathogens and their ability to cause localised complications in the head and neck.

- This case highlights the importance of the multispecialty approach that is required in medicine to diagnose, acutely treat and initiate long-term management plans for complex patients. approach to complex patients in order to optimise patient management when rare or unusual presentations occur.

Contributors KSY and KM: contributed to literature search, data acquisition and writing of manuscript. JSK: contributed to literature search, data acquisition and drafting of work. RN: contributed to literature search and drafting of work.

Funding The authors have not declared a specific grant for this research from any funding agency in the public, commercial or not-for-profit sectors.

Competing interests None declared.

Patient consent for publication Obtained.

Provenance and peer review Not commissioned; externally peer reviewed.

\section{REFERENCES}

1 Hippisley-Cox J, Pringle M, Ryan R. Stroke: prevalence, incidence and care in general practices 2002 to 2004. final report to the National stroke audit team. London: Royal College of Physicians, 2004.

2 Lee S, Shafe ACE, Cowie MR. Uk stroke incidence, mortality and cardiovascular risk management 1999-2008: time-trend analysis from the general practice research database. BMJ Open 2011;1:e000269.

3 Goldstein L. 407 ischemic cerebrovascular disease. In: Goldman L, Andrew I, eds. Goldman-Cecil medicine. 25th edn. Elesivier, 2015: 2434-6.

4 Panel C, Mohr JP, Albers GW. Etiology of stroke. Stroke 1997;28:1501-6.

5 DeMuri GP, Wald ER. 63- Sinusitis. In: Bennett J, Dolin R, Blaser M, eds. Mandell, Douglas, and Bennett's principles and practice of infectious diseases. 8th ed. Elsevier, 2015: 774-84.

6 Charakorn N, Snidvongs K. Chronic sphenoid rhinosinusitis: management challenge. J Asthma Allergy 2016:9:199-205.

7 Lee WH, Kim J-W, Lim J-S, et al. Chronic rhinosinusitis increases the risk of hemorrhagic and ischemic stroke: a longitudinal follow-up study using a national sample cohort. PLoS One 2018;13:e0193886.

8 Wong AM, Bilaniuk LT, Zimmerman RA, et al. Magnetic resonance imaging of carotid artery abnormalities in patients with sphenoid sinusitis. Neuroradiology 2004;46:54-9.

9 Macdonald RL, Findlay JM, Tator CH. Sphenoethmoidal sinusitis complicated by cavernous sinus thrombosis and pontocerebellar infarction. Can J Neurol Sci 1988;15:310-3.

10 Perez Barreto M, Sahai S, Ameriso S, et al. Sinusitis and carotid artery stroke. Ann Otol Rhinol Laryngol 2000;109:227-30.

11 Steadman CD, Salmon AHJ, Tomson CRV. Isolated sphenoid sinusitis complicated by meningitis and multiple cerebral infarctions in a renal transplant recipient. Nephrol Dial Transplant 2004;19:242-4.

12 Han JK, Kerschner JE. Streptococcus milleri: an organism for head and neck infections and abscess. Arch Otolaryngol Head Neck Surg 2001;127:650.

13 Watkins LM, Pasternack MS, Banks M, et al. Bilateral cavernous sinus thromboses and intraorbital abscesses secondary to Streptococcus milleri. Ophthalmology 2003;110:569-74.

14 Willcox MD. Potential pathogenic properties of members of the "Streptococcus milleri" group in relation to the production of endocarditis and abscesses. J Med Microbiol 1995;43:405-10.

Copyright 2021 BMJ Publishing Group. All rights reserved. For permission to reuse any of this content visit

https://www.bmj.com/company/products-services/rights-and-licensing/permissions/

BMJ Case Report Fellows may re-use this article for personal use and teaching without any further permission.

Become a Fellow of BMJ Case Reports today and you can:

- Submit as many cases as you like

- Enjoy fast sympathetic peer review and rapid publication of accepted articles

- Access all the published articles

- Re-use any of the published material for personal use and teaching without further permission

Customer Service

If you have any further queries about your subscription, please contact our customer services team on +44 (0) 2071111105 or via email at support@bmj.com.

Visit casereports.bmj.com for more articles like this and to become a Fellow 